ECONOMIC GROWTH CENTER

YALE UNIVERSITY

P.O. Box 208629

New Haven, CT 06520-8269

http://www.econ.yale.edu/ egcenter/

CENTER DISCUSSION PAPER NO. 948

\title{
Interpersonal, Intertemporal and Spatial Variation in Risk Perceptions: Evidence from East Africa
}

\author{
Cheryl Doss \\ Yale University \\ John McPeak \\ Syracuse University \\ Christopher Barrett \\ Cornell University
}

November 2006

Notes: Center Discussion Papers are preliminary materials circulated to stimulate discussions and critical comments.

This study was conducted as part of the Pastoral Risk Management Project of the Global Livestock Collaborative Research Support Program, funded by the Office of Agriculture and Food Security, Global Bureau, USAID, under grants DAN-1328-G-000046-00 and PCE-G-98-00036-00. The opinions expressed do not necessarily reflect the views of the U.S. Agency for International Development. Doss:

cheryl.doss@yale.edu; McPeak: jomcpeak@maxwell.syr.edu; Barrett: cbb2@cornell.edu.

This paper can be downloaded without charge from the Social Science Research Network electronic library at: http://ssrn.com/abstract $=946450$

An index to papers in the Economic Growth Center Discussion Paper Series is located at: http://www.econ.yale.edu/ egcenter/research.htm 


\title{
Interpersonal, Intertemporal and Spatial Variation in Risk Perceptions: Evidence from East Africa
}

Cheryl Doss, John McPeak, and Christopher Barrett

\begin{abstract}
This study investigates variation over time, space and household and individual characteristics in how people perceive different risks. Using original data from the arid and semi-arid lands of east Africa, we explore which risks concern individuals and how they assess their relative level of concern about these identified risks. Because these assessments were gathered for multiple time periods, sites, households and individuals within households, we are able to identify the degree to which risk perceptions vary across time, across communities, across households within a community, and across individuals within a household. We find the primary determinants of risk rankings to be changing community level variables over time, with household specific and individual specific variables exhibiting much less influence. This suggests that community based planning and monitoring of development efforts that address risk exposure should be prioritized. We also find that individuals throughout this area are most concerned about food security overall, so that development efforts that directly address this problem should be given the highest priority.
\end{abstract}

Key words: $\quad$ Risk ranking, risk perceptions, intrahousehold, Africa, Kenya, Ethiopia JEL Codes: O12, D80, Q0 
Residents of the arid and semi-arid lands (ASALs) of east Africa are exposed to myriad risks. Some originate from the nature of the pastoral production system that is the main economic activity in these areas. ASALs have rainfall patterns that are highly variable temporally and spatially, making pasture and water availability for livestock unpredictable. In addition, pastoral reliance on livestock to convert pasture and water into food for human use exposes pastoralists to risk though loss or diminished productivity of these livestock. Other risks originate from government policy; for example, livestock sales used to generate cash to buy food can be suddenly halted due to the imposition of quarantine. The lack of government presence can also lead to risk exposure; for example, formal security services and border defense are weak in these areas. Finally, the relatively poor infrastructure found in these areas makes ex ante forecasting of these risks problematic - information dissemination is often lacking of forecasts that are generated and the forecasts are often too coarse to be of much use (Luseno et al, 2003). It also makes ex post coping with risks difficult, as roads, health centers, veterinary services and markets are poorly maintained or non-existent.

We designed this study to investigate how residents of ASALs perceive risks facing their households. We wanted to understand what risks people are concerned about. In addition, we wanted to understand the degree to which risk perceptions varied across time, across communities, across households within a community, and among individuals within a household. Appropriate policy responses to these risky environments clearly depend on how the risks vary across time and space and how they vary across and within households.

Expressed risk perceptions are based not only on the objective risks that individuals face - such as the probability of low rainfall - but also on their subjective assessment of their exposure to different shocks. Their subjective assessments combine their expectations about the 
likelihood of different events occurring with their beliefs about their own abilities to deal with various contingencies. Even in environments such as the ASALs of northern Kenya and southern Ethiopia, where covariate risks such as drought, infectious disease, and armed violence feature prominently, individual household members - much less different households or communities - may perceive the risks they face quite differently. As a consequence, the welfare and behavioral effects of risk may differ across individuals, households and communities, and over time. Interventions and policies intended to help vulnerable peoples manage risk - either through ex ante mitigation strategies or through ex post coping mechanisms, including external transfers such as food aid, may need to account for such variation in order to prove effective. More nuanced understanding of the variation in subjective perceptions of risk can inform the design and targeting of policies, research and interventions to address objective sources of risk. A small, relatively recent literature explores patterns of variable risk assessment with respect to individual risks, such as asset price shocks, weather, or disease. ${ }^{1}$ However, there is scant empirical evidence that explores subjective risk perceptions across a range of stochastic phenomena, especially in the context of developing countries. So while the literature tells us something about how individual characteristics might affect risk perceptions with respect to a given contingency, it is relatively silent with respect to how individuals' ordering of concerns varies over space, time and individual characteristics. Scarce resources necessitate prioritization of interventions, however, and it would make sense to match these interventions to the concerns reflected in the risk rankings of intended beneficiaries.

This paper offers what we believe to be the first study to explore how individuals' subjective risk rankings among a range of potential perils vary across individuals, households,

\footnotetext{
${ }^{1}$ See Rabin (1998) for an excellent survey.
} 
space and time. We exploit a unique quarterly panel data set from northern Kenya and southern Ethiopia that covers a 2.5 year period of drought and recovery. We use a participatory risk ranking method developed in this area (Smith et al. 2000) and build on an earlier, cross-sectional study among the same population that used focus groups, rather than individual-level survey data, to establish that wealth, gender, and location affected the perceptions of risk (Smith et al. 2001). The individual-level survey data permit us to probe deeper on the issue of cross-sectional heterogeneity in risk assessment, enabling us to explore gender, power and wealth differences that were coarse in Smith et al.'s (2001) groups data. Moreover, the longitudinal dimension of the data permit us to study not only seasonality, but also, more interestingly, the extent to which past shocks, both those suffered by the respondent household and those experienced by others in the local community, affect risk perceptions. Previous work in the region on climate forecasting found strong evidence of partial updating of climate risk assessments in response to new information conveyed by climate forecasts (Lybbert et al. forthcoming). We explore, more generally, whether there appears to be updating of risk assessments across a range of risks in response to personal experience or observation of shocks.

\section{Risk Perceptions}

Some risks faced by individuals in ASALs can be measured - or at least estimated objectively, including the probability of below-normal rainfall, disease outbreaks, armed violence and poor market prices for the livestock they sell or the grain and other basic necessities they buy. Yet these risks are rarely estimated and communicated at the spatio-temporal scales 
relevant to individuals' choices. ${ }^{2}$ Moreover, research in a variety of fields suggests that people's behavior is influenced not only by the measurable, objective risks that they face but also, perhaps especially, by their subjective perceptions of risks and the possible consequences of different events (Kahneman and Tversky, 1982).

The policy implications are important. The WHO Health Report for 2002 notes, "During the 1980s, scientific predictions were seen to be rational, objective and valid, while public perceptions were believed to be largely subjective, ill-informed and, therefore, less valid" (p.30). They note that this has changed as public interest and pressure groups gained the ability to argue for their own assessments and interpretations of risks. "Risk had different meanings to different groups of people and ... all risks had to be understood within the larger social, cultural and economic context" (p. 31). Slovic (1987) emphasizes that public policy dialogue with respect to risk management evolves only modestly in response to the introduction of new, credible scientific evidence on objective risk exposure because strongly-held prior beliefs affect the way information is processed and people update beliefs.

Subjective risk perceptions are particularly valuable because they incorporate multiple factors, including the individual's understanding of the objective risks, the individual's expectations about his or her own exposure to risks, and his or her ability to mitigate (ex ante) or cope (ex post) with the adverse events if they occur. Individual capacity to manage risk can feed back into risk perceptions. As a result, people often ignore new information altogether - socalled "belief perseverance" - or willfully misread new evidence as supporting prior beliefs, a

\footnotetext{
${ }^{2}$ For example, Luseno et al. (2003) emphasize that improvements in seasonal climate forecasting in the ASALs of east Africa are not affecting household level behavior in part because the spatial resolution remains too coarse to be of much use to individual decision-makers.
} 
tendency called "confirmation bias" (Darley and Gross 1983, Kahneman and Tversky 1982, Lord, et al. 1979, Plous 1991, Rabin and Schrag 1999, Tversky and Kahneman 1982). Such biases in learning then affect individuals' forecasts of stochastic events and the pace at which they update their beliefs in response to new information, especially when their welfare depends on the realization of the stochastic variable, in which case individual preferences introduce further cognitive bias, with preference-consistent information often accepted uncritically while preference-inconsistent data are processed critically ( Nisbett and Ross 1980, Kunda 1990, Ditto and Lopez 1992).

Although much of the early work on risk perceptions was done in developed countries, a recent literature has focused on risk perceptions in Africa, especially around the issues of HIV/AIDS. The simplest studies of risk perceptions focus on how well people understand objectively measurable risks. This allows researchers to see whether factual information is accurately understood. For example, Buhler (2003) asked respondents whether sexual intercourse was a way of becoming infected with HIV/AIDS. This approach helps to identify information gaps, but it does not account for the possibility that people may see certain risks as unimportant if they believe that their behavior can mitigate their personal risk exposure.

Other research has pushed further. Many researchers have begun to ask about the extent to which an individual perceives him or herself to be at risk. One way to measure risk perception is to ask people an intensity measure with regard to a specific risk. For example, a survey in Malawi asks people to say whether they perceive their risk of HIV/AIDS to be none, small, moderate or great (Behrman et al, 2003). Their answers were presumably based on their understanding of the causes of AIDS and their own assessment of whether or not they were engaging in behaviors that might lead to HIV/AIDS. 
A further way to measure subjective risk perceptions is to ask people to rank different risks. This does not give an intensity measure, but it does provide an ordinal measure that is important when one needs to prioritize the allocation of scarce resources, as is chronically the case considering development alternatives in the ASALs of Africa. Early work of this type asked American respondents to estimate the number of deaths for 40 different hazards and compared these with known statistical estimates. Results indicated that people tend to overestimate the number of deaths from rarer and infrequent risks, while underestimating considerably those from common and frequent causes, such as cancer and diabetes. "However, people's rank ordering by the total number of deaths does usually correspond well overall with the rank order of official estimates" (Lichtenstein et al, and Fischloff et al, cited in WHO, p. 32).

These measures of risk perceptions have been used in empirical analyses, both as explanatory variables and outcome variables. As explanatory variables, the issue is typically whether the risk perceptions affect individual behavior. These studies raise serious concerns about endogeneity, but they raise interesting questions nonetheless. For example, in urban Cameroon, young people's perception of whether or not they were at high risk for contracting HIV/AIDS was shown to be positively correlated with condom use (Meekers and Klein, 2002). Behrman, et. al (2003, p. 2) note, however, that "very little research has focused on the determinants of subjective risk assessments.” For example, the perceived threat of HIV/AIDS depends on both individual subjective risk and the ability to respond behaviorally. In the context of understanding HIV/AIDS, several studies have suggested that network effects are important in shaping both risk perceptions and behavior (Behrman et al.2003, Buhler et al.2003). Smith et al. (2000) document how subjective perceptions of the risk of violent conflict vary directly with proximity to ethnic frontiers in the Horn of Africa. Lybbert et al. (forthcoming) explore how 
recent rainfall and forecast information affect pastoralists' beliefs about the likelihood of different rainfall patterns in this same region.

Gender has been widely considered in studies of risk perceptions, largely to test the hypothesis that women are more risk averse than men. This may show up in a number of different ways. Studies of the financial sector and investment behaviors sometimes find gender differences in willingness to take risks. For example, when asked about the amount of financial risk that an individual and his or her spouse were willing to take with their savings and investments, $60 \%$ of female respondents, but only $40 \%$ of male respondents, said they were unwilling to take any risks (Jianakoplos and Bernasek, 1998). Using an experimental design with three decision environments, Eckel and Grossman (2003) find a significant sex difference in risk aversion. In addition, they find that both men and women predict that women will be more risk averse in these situations. Schubert et al. (1999), however, suggest that such results may be due solely to differences in men's and women's opportunity sets, rather than their attitudes.

The literature on risk perceptions thus offers relatively little evidence on the correlates of alternative assessments of individual risks and, as best as we can tell, no evidence on how individuals rank distinct risks they face nor how such assessments might evolve over time in response to seasonal patterns or the arrival of new information. By studying the risk perceptions of individuals from communities facing a range of serious risks that may vary across space, time and household or individual characteristics, we hope to shed new light on this important issue.

\section{Study Area and Survey Data}

From March 2000 through June 2002, the USAID Global Livestock Collaborative Research Support Program (GL CRSP) “Improving Pastoral Risk Management on East African 
Rangelands" (PARIMA) project collected quarterly survey data from 330 households in ten communities within a single, contiguous livestock production and marketing region in the arid and semi-arid lands of northern Kenya and southern Ethiopia. The specific sites were chosen to capture relative variation in agricultural potential, market access, livestock mobility and ethnic diversity (Table 1). Rainfall is low and variable and the study period coincides with a major drought that affected much of the area in 2000 and continued well into 2001 in some sites. The infrastructure is extremely weak throughout the region, in terms of roads, schools, and health facilities.

In each household, we interviewed the household head and, if applicable, one randomly selected spouse and one randomly selected non-head/non-spouse adult (age 18 years or older) in the household. The household head answered questions regarding the income, assets, and activities of the entire household. The other individuals surveyed reported on their own assets, incomes and activities. In addition to these standard household survey questions about income, consumption, activities and livestock herds, we asked respondents to assess whether they were concerned that an item on a list of twelve different types of risks common in the study area could adversely affect their household in the coming three months. ${ }^{3}$ For any risks they said they were concerned about, we followed up by asking them to rank these risks from the one they were most concerned about to the one they were least concerned about. Thus, for each household, we have up to three respondents, enabling us to look not only at how risk perceptions vary across households, but also how they vary within households by gender, age or status.

\footnotetext{
${ }^{3}$ The first eleven items on the list were based on the findings of the Smith et al. (2000) study and pre-testing of the questionnaire, and the twelfth item was "other" to allow flexibility. Very few "other" responses were recorded, so we will focus on the 11 specific concerns described below.
} 
In each site, a baseline survey was conducted in March 2000. Repeat surveys were conducted quarterly for an additional nine periods, through June 2002. The repeated survey recorded information both on events occurring during the three-month period preceding the fielding of the survey and respondents' subjective risk assessments for the upcoming threemonth period. The quarterly interval of the survey was designed to correspond to the bimodal distribution of rainfall in the study area. Thus, for example, a survey fielded in June recorded information on the period during which the long rains usually fall (March / April / May) as well as forecasts for what is usually the ensuing dry season (June / July / August).

Table 2 presents sample descriptive statistics. Educational attainment is very low; 88 percent of those interviewed had completed no schooling at all. Mean income - which includes the value of goods produced and consumed within the household (most notably milk and meat), wages, salaries, remittance and business income - valued at approximately 76 Kenyan Shillings/US dollar or 8.5 Ethopian Birr/ US dollar ${ }^{4}$, was less than $\$ 76$ per month per household in the period from April 2000-July 2000. On average, households rely on livestock and livestock products for 73 percent of their income, although the median level is higher. Fifty-four percent of households receive all of their income from livestock, while 19 percent report receiving no income at all from livestock. This underscores that communities in ASALs include both pure herding households - those almost wholly reliant on their livestock for their livelihoods - those who have "dropped out" of the pastoral system and live in towns, commonly relying on food aid, casual labor, and small-scale activities such as producing charcoal, brewing alcohol or selling

\footnotetext{
${ }^{4}$ For the analysis, Ethiopian birr was converted into Kenyan shillings at the exchange rate for that period. The exchange rate for Kenyan shillings ranged from 76-79 per US dollar and for Ethiopian birr from 8.21-8.56 Birr/US dollar.
} 
firewood, and those who have diversified beyond pastoral activities into full-time wage work or business. As noted for this area by earlier studies (McPeak and Little 2005, Little 1985), settling in towns attracts the poor who have no other options and the wealthy who diversify into town based activities with higher returns while maintaining herding through family or contract labor, leaving non-sedentarized those who tend to comprise the middle portion of the income distribution and who are most reliant on livestock.

The median age of those interviewed is 45.5 . Of those interviewed, 49 percent were the head of household. One third of these household heads were women. Twenty-nine percent of those interviewed were wives of the head, while 22 percent were other adults in the household, neither the head nor the wife of the head.

\section{Risk Rankings}

We seek to understand how risk perceptions vary among residents of the ASALs of east Africa across a variety of risks as well as how those perceptions vary over time in response to seasonality and the experience of shocks by respondents or those close to them. We expect several factors to affect risk perceptions. Individual characteristics such as gender, headship, age and education may affect both objective risk exposure and one's ability to mitigate risk ex ante or to cope with it ex post. Since risk assessments result from each of those processes, individual attributes may matter. Household level characteristics such as wealth, income, and household size may similarly affect risk exposure and mitigation and coping ability. Location-specific, time invariant effects may partially reflect cultural and community factors, such as the existence of strong social safety nets or effective conflict resolution mechanisms, which influence 
perceptions of risk. These location effects may also reflect variation in culturally determined gender roles that place responsibility for managing particular sorts of risks on men or women.

As already mentioned, from each respondent we obtained rankings of a series of risks facing his or her household. In each period, each respondent was told, "We know that households in this area are concerned about problems that could happen to them. We have made a list of concerns people commonly tell us about. I am going to read you this list of concerns, and I would like you to tell me which of these you are afraid could affect your household in the coming three months." Note that the question is explicitly about prospective risk for the coming season; it is not retrospective. The specific risks enumerated included: lack of pasture for animals, insufficient water for animals, animal sickness or death, animal loss due to theft or raiding, physical insecurity and violent conflict, human sickness, no buyers for animals you wish to sell, low prices for animals you wish to sell, food shortages, high prices for things you buy, crop failure, and an open-ended "other" option.

After identifying the risks that the individual was concerned about, respondents were asked in a follow up question to rank those risks that they identified as ones they were worried about in order of concern, from greatest worry to least. Therefore, these responses are ordinal rather than cardinal measures. ${ }^{5}$ Moreover, each individual ranked only those items that he or she identified as a positive concern. Therefore the relevant set of enumerated risks varies across respondents. The risk rankings cannot be interpreted as absolute intensity measures, only as measures of relative importance of each concern to the particular respondent at a particular point in time. A specific risk's ranking may fall (rise) over time for an individual respondent because

\footnotetext{
${ }^{5}$ Ties were allowed. If two risks were viewed as of equal concern, they were assigned the same value for the ranking, and the next item ranked was assigned the value of the tied rank plus two.
} 
that issue becomes less (more) of a concern or because another issue becomes more (less) of a concern.

The ordinality and varied dimensionality of the data force some difficult methodological choices, as Smith et al. (2001) discuss in detail. Our approach, following Smith et al., who found similar outcomes across different possible estimation methods with such data, is to normalize and convert the rankings so that we evenly space each individual's rankings across the 0 to 1 interval, where 0 means not a concern and 1 reflects the respondent's greatest concern. The risk assessment index thus becomes $R_{i j}=1-\left(\left(r_{i j}-1\right) / n_{i}\right)$ for individuals $i=1 \ldots m$ and risks $j=1 \ldots n_{i}$ where $r_{i j}$ is the ordinal, integer risk ranking reported by the respondent and $n_{i}$ is the number of risks ranked by individual $i .^{6}$ For example, if three items were ranked, the concern rated as the most serious by individual $I$ thus receives the ranking $R_{i j}=1-((1-1) / 3)=1$, the second receives the ranking $R_{i j}=1-((2-1) / 3)=2 / 3$, and the third receives the ranking $R_{i j}=1-((3-1) / 3)=1 / 3$. Each of the other concerns, none of which was ranked by $i$, would be assigned $R_{i j}=0$.

The mean rankings offer a crude indicator of the relative importance of each source of risk, aggregated across each interviewee and time period. The highest ranked concern was a fear that there would be food shortages (Table 3). This was followed by a related concern for human health. Pastoral livelihood specific issues, most prominently adequate pasture for animals, appear only after these first-order concerns for food security and health. But there is considerable

\footnotetext{
${ }^{6}$ The other option would be to use a uniform distribution of intervals, which allows for an ordered multinomial estimation. The measure of risk rankings, $R$, would be calculated as follows: $\left.R_{i j}=1-\left(\left(r_{i j}-1\right) / n^{*}\right)\right)$ for individuals $i=1 \ldots m$ and risks $j=1 \ldots n$ where $n^{*}$ is the maximum number of risks identified by any respondent.
} 
variation over time and across respondents with respect to all of these rankings, with none of the risks unconditionally statistically significantly more prominent than any other concern.

We had expected that individual characteristics, especially gender, would affect the risk rankings. Simple bivariate correlations suggest, however, that such effects are modest at best. Figure 1 shows the ranking of each of the eleven concerns by gender. It suggests that there is almost no difference in risk ranking by gender. Nor is there a difference in the number of items ranked by gender (men ranked an average of 6.45 and women an average of 6.28 , a statistically identical count).

Time and place variables, however, are strongly associated with variation in risk rankings (Figures 2-3). Figure 2 shows the risk ranking by location for the five top concerns. Figure 3 shows the risk rankings for these five concerns over time. Within country differences appear greater than between country differences, suggesting that agroecological factors trump policy differences between the two nations in driving variation in risk assessments. This interpretation is reinforced by the steady fall over time in the number of concerns raised, from an average of 8.1 in June of 2000 to 3.6 in June 2002. As the drought situation improved, people said that they were concerned about fewer things happening in the following three months.

These results raise the question as to whether this spatio-temporal variation in risk assessments within a stable population reflects responses to different recent experiences - i.e., local shocks cause localized updating of subjective risk assessments - rather than just unconditional seasonality and time-invariant location-specific effects. Multivariate econometric analysis allows us to look at this issue and to probe in greater depth the preceding associations observed (or not observed) in simple cross-tabulations. 
Because our dependent variable, the risk assessment, $R_{i j} \in[0,1]$, falls in an interval we use a doubly censored Tobit estimator applied to the full rankings data. The independent variables include individual characteristics such as gender, age, the highest grade attained, and status within the household (head or wife of head, with "other" as the omitted variable). We expected to find differences based on gender, wealth, and location based on the focus group study in this area (Smith, et al. 2001) Age, education and head status may affect both the individual's perception of their household's exposure to risk as well as their ability to manage it. Household characteristics included as regressors are TLU holdings, the self-reported cash value of nonlivestock assets, full household income, share of income earned from livestock and livestock products, share of income earned from salary or wages (a relatively stable source of income in this region), and household size. We also include seasonal and annual dummy variables (with the December survey round dummy - reflecting concerns for the upcoming dry season that follows the "short" October-December rains - and the 2002 year dummy as the omitted variables). The June survey captures perceptions looking forward to the dry season following the period of the March-May "long” rains. The March and September rounds thus capture perceptions looking forward to the respective rainy seasons. The drought was most severe in 2000 , and by 2002 all of the surveyed areas were in a recovery phase.

Given the unconditional variation in risk rankings across time and space, we probe further as to whether this reflects spatial path dependence, recurrent seasonality, or perhaps localized beliefs updating in response to local shocks. In particular, we explore how the events of the previous period affect how people perceive the risks they face in the coming period. The data allow us to look at both household and community level shocks. At the household level, we have information on changes in household herd size (herd size at the end of the most recent 
period minus herd size at the end of the preceding quarter), whether any household member experienced an illness or injury in the previous three months that prevented him or her from working, and whether any household member died in the previous period.

At community level, we control for the mean percentage change in household herd sizes within the respondent's community over the previous survey period, for the occurrence of any livestock raids, animal quarantines, or outbreaks of animal or human diseases in the community during the previous quarter, for the deviation of monthly consumer prices from their mean over all months in that location, for the number of livestock traders buying animals in the community in the previous three months, and for a subjective indicator variable, collected each month from key informants, as to the ease of selling livestock, with above normal assigned a value of 1 , normal 0 , and below normal -1 . These covariates permit us to study how individual risk assessments respond to shocks occurring in the community around them, controlling for the shocks they experience directly and other individual and household attributes, which represents a "learning from others" effect quite distinct from the learning effect associated with their own experience. ${ }^{7}$ Table 4 reports the means of these shock variables. ${ }^{8}$

\footnotetext{
${ }^{7}$ This is analogous to the distinction in the technology adoption literature between "learning by doing" and "learning from others" (Foster and Rosenzweig 1995, Moser and Barrett 2006).

${ }^{8}$ Note that there are fewer observations for the community level data as some community surveys from the later periods are not available.
} 


\section{Regression Results}

Table 5 presents the key results for the top five concerns reported. ${ }^{9}$ Site, season and year variables were included in the estimations, but we omit those coefficient estimates from the table in the interest of conserving space. ${ }^{10}$

Each of the community-level shock variables was statistically significant in explaining the ranking of at least one of the concerns at a 5\% level of significance, with the lone exception of the outbreak of animal disease which was significant at the $10 \%$ level for two concerns. Wald tests found the community level shocks were jointly statistically significant at the one percent level for each of the eleven risks studied. ${ }^{11}$ Plainly, individual level risk assessments respond significantly to broader, community-level shocks, indicating information flow and social learning with respect to risk.

Once we control for community-level variables, household-level characteristics and shocks have surprisingly modest effects on risk rankings. There are only two household characteristics, asset value and income, that had a significant impact at the $5 \%$ level on more than one of the top five concerns reported in table 5. Household size and herd size impact one ranking each at a 5\% significance level. Jointly, household level characteristics were statistically significantly associated, at the one percent level, with individual-level risk rankings for only 6 of

\footnotetext{
${ }^{9}$ Results for the other concerns are available from the authors on request but do not differ
} qualitatively from what we report here.

${ }^{10}$ The site dummies are jointly significant at the $1 \%$ level for all risk rankings as are the time dummies by Wald tests.

${ }^{11}$ A table summarizing the Wald test results for all 11 risks ranked is available from the authors by request. 
the 11 risks enumerated, in striking contrast to the community-level characteristics that were uniformly highly statistically significant. Even more surprisingly, household-level shocks had little effect on individuals' risk rankings. Illness is the only household shock variable that is associated at a 5\% significance level in the results in table 5, and this is only for one of the risks. Change in herd size is significant for one ranking at the $10 \%$ level and the indicator of a recent death in the family is not significant for any of the rankings presented in table 5. Joint Wald tests indicate that household-level shocks were not statistically significant at the one percent level in explaining individual rankings with respect to any of the 11 risks we study. Once one controls for household and community characteristics and community-level shocks, households' idiosyncratic risk experiences seem to have negligible effect on individuals' risk perceptions.

Finally, we consider the impact of individual characteristics. The only variable that is significant at the $5 \%$ level or better in more than one ranking reported in table 5 is whether or not the individual is a head of household. The variable recording whether the individual is a male is significant at the 5\% level for only one of the risks in table 5. The variable recording whether the individual is a female head of household is significant at the $10 \%$ level only and for only one of the risks in table 5. Age, education, and status as a wife are do not significantly influence the rankings of any of the top five concerns. Wald test results illustrate that individual characteristics had a relatively modest impact on individual risk rankings, being jointly statistically significant at the one percent level for only 6 of 11 risks.

Figures 4-6 and Table 6 illustrate the quantitative significance of these overall patterns by considering the joint impact of various variables through simulation of estimation results. We use these simulations to contrast the following: changes in rankings over time within a site; changes in rankings over time across sites; changes in rankings aver time across households in a given 
site; and finally changes in rankings across individuals within a site. These simulations based on multivariate regression results provide a direct comparison with the unconditional results previously depicted in Figures 1-3.

Figure 4 illustrates how the risk rankings in one community are affected by the community level variables over time. It shows simulated risk rankings over time in the North Horr (Kenya) study site for the five risks that received the highest ranking over all periods for this site. To generate these results, household and individual variables are held at the site specific means for all time periods, the North Horr site dummy is set to one and other site dummies are set to zero, the site specific and time specific community level variables (raids, quarantines, ease of selling animals, number of traders, animal disease outbreaks, price deviation, community average herd size, community average change in herd size, rainfall variables) and time variables (seasonal and year dummy variables) are inserted into the estimation results as they change over time.

Figure 5 conducts a similar exercise, contrasting two very different sites. It shows the risk rankings over time for two communities, North Horr (Kenya) and Finchawa (Ethiopia), for the concern that there will be food shortages, which is the risk ranked the highest overall.

Figure 6 returns to the contrast between Finchawa and North Horr over time, but holds community level variables constant while allowing the household level variables to change. In this case, the community level variables are fixed at the means calculated over all time periods for the given site, individual level variables are held fixed at their site specific means for all periods, but time period specific household level variables (herd size, change in herd size, illness, death, asset level, income level, share of income from livestock, share of income from salary, 
and household size) are calculated for the highest and lowest quartile with herds arranged by size at each point in time. Site-specific herd size and year and season dummies are included.

Finally, in table 6, we turn to the question of the impact of individual characteristics on risk rankings. We present simulation results that contrast male and female rankings for the Finchawa site for the five highest ranked risks in table one. In this case, the site and time specific variables for individual variables (age, education, and status within the household) for males and for females are calculated separately, then used in the simulation, with all other variables held at their site specific means over all time periods.

Overall, these simulations clearly reinforce the finding that risk rankings vary highly across sites and across time. Although risk rankings are influenced by household- and individual-specific characteristics, in these data the major source of variation appears to be across sites and across time, rather than across individuals or households within a given site.

\section{Conclusions}

The clear and important results of this analysis are four. First, risk perceptions vary markedly across time, which has important practical implications. Common development practices such as Rapid Rural Appraisal, in which researchers drop into a village for a brief visit to ask about needs and concerns, may give results that are far more time-bound than is commonly appreciated. Within just a 27 month period, we observed both sharp seasonality and striking interannual changes in risk rankings that call into question the generalizability of static, snapshot assessments of risk in dynamic communities. Figure 4 illustrates that no single risk is at the top of the list for all time periods. In fact, we find that risk assessments respond especially sharply to recent local events, such as cattle raids, drought, the imposition of a quarantine for 
animal disease control, etc. Since rapid assessments are commonly fielded in response to such events, they may be especially prone to distortion. These results imply a need for ongoing, longitudinal monitoring of locations thought vulnerable to multiple risks in order that external interventions can adapt appropriately to changing risk profiles in dynamic settings such as the pastoralist areas of east Africa.

Second, variation in risk rankings is more pronounced between communities rather than within them. Figure 5 illustrates that the Finchawa and North Horr rankings differ in magnitude in most periods, and even cross at one point. They also do not show clear co-movement over time. Figure 6 and table 6 do indicate that there can be difference across households as stratified by herd wealth or across individuals based on gender, but these differences are much smaller than those we see in response to the spatial and intertemporal changes illustrated in figures ten and eleven. Within a community, variation in household and individual characteristics has some effect on individual-level risk rankings, reflecting important differences in social standing, economic opportunity and constraints, etc. But inter- and intra-household variation in risk rankings is relatively modest compared to the inter-community and inter-temporal variation. The dual, practical implication of this is that there needs to be community-specific planning to mitigate and cope with risk, because a single plan for the larger region runs the risk of overlooking community specific concerns, but that most of this variation is between rather than within communities, so that community-based monitoring and formulation of development plans may suffice. Our findings do indicate that a community plan that does not take into account the heterogeneity of concerns across and within households runs the risk of being biased towards a subset of community members, but given tight budgets, our results indicate that it is more 
important to push for finer grained analysis between different communities rather than within them.

Third, community-level shocks associated with rainfall, violence, animal and human disease, market conditions, etc. have a pronounced effect on individual-level risk perceptions, while household-level shocks associated with human illness and mortality or herd losses do not. This suggests that people learn actively from the experiences of others around them and adjust their risk assessments quickly in response, corroborating prior work in the area on subjective expectations of rainfall (Lybbert et al. forthcoming). Although covariate shocks are relatively weakly correlated with individual-level income and asset shocks in this area (Lybbert et al. 2004, Lentz and Barrett 2005), individuals appear to adapt their risk assessments more in response to community-level shocks than to those that strike their own household. This would also be consistent with the argument that social networks or sharing mechanisms within communities lead individuals to be less concerned about household specific shocks compared to community covariate shocks, though investigating this interpretation is left as a topic for further research.

Fourth and finally, the project that supported this research was premised on the idea that residents of ASALs are exposed to a high degree of risk, and that this risk is multidimensional. The goal was to understand this risk and its related vulnerability in order to identify development interventions that help mitigate and cope with these risks. While this study has placed much emphasis on understanding the differences across people and time periods in risk perceptions, it is worth taking a step back to look at the broader picture.

To do this, we close by returning to the finding that the most prevalent fear was of food insecurity. The fear of food insecurity is largely driven by the fact that the study area regularly suffers drought, herd loss, and sudden decreases in food (especially milk) availability. The 
perception of risk is highest for the core outcome of not having enough food, rather than underlying causes such as insufficient pasture, crop failure, high consumer prices or livestock mortality. Policy responses to food insecurity in the area continue to focus heavily on emergency assistance in the form of food aid, the implementation of which is often not timely or well targeted (Lentz and Barrett 2005). More stress also needs to be given to designing humanitarian assistance that is compatible with pastoralists' preferred drought mitigation strategy: migration (Morton, 2006; Aklilu and Wekesa 2002). Food aid is all too often distributed from towns, which discourages mobility to remote rangelands (McPeak, 2003).

Beyond the issue of food insecurity, we close by noting a few other findings in the risk rankings that merit special note. Human sickness is a major concern throughout the study area. Health services are minimal and improving them would help address this risk. Another finding is that lack of pasture is a much greater concern than lack of water, suggesting that pasture rather than water is viewed as the more binding constraint on pastoral production in this area. Finally, as the insecurity in this area is often characterized as a result of "cattle rustling", it is worth noting that the results indicate the fear of losing animals in a raid is relatively minor in our results compared to the fear of insecurity. Individuals in this area are viewing insecurity as multi-dimensional, suggestion policy responses must go beyond anti-stock theft efforts. 


\section{References}

Aklilu, Y. and Wekesa, M. (2001). Livestock and livelihoods in emergencies: Lessons learned from the 1999-2001 emergency response in the pastoral sector in Kenya. Feinstein International Famine Center Working Paper \#3, Tufts University.

Behrman, J.R., Kohler, H.-P. and Watkins, S.C. (2003). Social networks, HIV/AIDS and risk perceptions. Penn Institute for Economic Research Working Paper 03-007. University of Pennsylvania.

Buhler, C. and Kohler, H.-P. (2003). Talking about AIDS: The influence of communication networks on individual risk perceptions of HIV/AIDS infection and favored protective behaviors in South Nyanza District, Kenya. Demographic Research. Special Collection 1, Article 13, Sept. 19, 2003. pp. 398-437.

Darley, J. M., and Gross, P. H.. (1983). A Hypothesis-Confirming Bias in Labeling Effects. Journal of Personality \& Social Psychology 44(1): 20-33.

Ditto, P. H., and Lopez, D. F. (1992). Motivated Skepticism: Use of Differential Decision Criteria for Preferred and Nonpreferred Conclusions. Journal of Personality \& Social Psychology 63(4): 568-584.

Eckel, C.C. and Grossman, P.J. (2003). Forecasting Risk Attitudes: An Experimental Study of Actual and forecast risk attitudes of women and men. Processed. Virginia Tech, Blacksburg, Virginia.

Fischloff, B., and Lichtenstein, S. (1981). Acceptable Risk. New York: Cambridge University Press. 
Foster, A. and Rosenzweig, M. (1995). Learning By Doing and Learning from Others: Human Capital and Technical Change in Agriculture. Journal of Political Economy 103: 11761209.

Jianakoplos, N. A. and Bernasek, A. (1998). Are women more risk averse? Economic Inquiry, 36(4): .620-30.

Kahneman, D., and Tversky, A. (1982). Subjective Probability: A Judgement of Representativeness, in D. Kahneman, P. Slovic, and A. Tversky ed., Judgment under uncertainty: heuristics and biases, (Cambridge ; New York, Cambridge University Press), pp. 32-47.

Kunda, Z. (1990) The Case for Motivated Reasoning. Psychological Bulletin 108(3): 480-498.

Lentz, E. C. and Barrett, C.B. (2005). Food aid targeting, shocks and private transfers among East African pastoralists," Cornell University working paper.

Lichtenstein, S., Slovic, P., Fischhoff, B., Layman, M. and Combs, B. (1978). Judged frequency of lethal events. Journal of Experimental Psychology: Human Learning and Memory. 4: $551-78$.

Lord, C. G., Ross, L. and Lepper, M.R. (1979). Biased assimilated and attitude polarization: The effects of prior theories on subsequently considered evidence." Journal of Personality \& Social Psychology 37(11): 2098-2109.

Luseno, W.K., McPeak, J.G., Barrett, C.B., Gebru, G. and Little, P.D. (2003). The value of climate forecast information for pastoralists: Evidence from Southern Ethiopia and Northern Kenya, World Development, 31(9): 1477-1494. 
Lybbert, T.J., Barrett, C.B., McPeak, J.G., and Luseno, W.K. (Forthcoming). Bayesian herders: Updating of rainfall beliefs in response to external climate forecasts. World Development.

Lybbert, T.J. , Barrett, C.B., Desta, S., and Coppock, D.L. (2004). Stochastic wealth dynamics and risk management among a poor population, Economic Journal, 114(498): 750-777.

McPeak, J. (2003). Analysing and addressing localized degradation in the commons. Land Economics. 79(4): 515-536.

Meekers, D. and Klein, M. (2002). Determinants of condom use among young people in urban Cameroon. Studies in Family Planning, 33(4): 335-346.

Morton, J. 2006. "Pastoral coping strategies and emergency livestock market intervention.” In Pastoral Livestock Marketing in Eastern Africa: Research and Policy Challenges. John McPeak and Peter Little (eds.). Intermediate Technology Publishing, Warwickshire, UK. Pages 227-246.

Moser, C. and Barrett, C.B. (2006). The complex dynamics of smallholder technology adoption: The case of SRI in Madagascar," Agricultural Economics. In press.

Nisbett, R. E., and Ross, L. (1980). Human inference : strategies and shortcomings of social judgment. Englewood Cliffs, N.J.: Prentice-Hall.

Plous, S. (1991). Biases in the assimilation of technology breakdowns: Do accidents make us safer?" Journal of Applied Social Psychology 21(13): 1058-82.

Rabin, M. (1998). Psychology and economics. Journal of Economic Literature 36(1): 11-46.

Rabin, M., and Schrag, J. (1999). First impressions matter: A model of confirmatory bias." Quarterly Journal of Economics 114(1): 37-82. 
Shubert, R., Brown, M., Gysler, M. and and Branchinger, H.W. (1999) Financial decisionmaking: Are women really more risk averse? American Economic Review, 89(2): 38185.

Slovic, P. (1987). Perception of risk. Science 236(17): 280-285.

Smith, K., Barrett, C., and Box, P. (2001). Not necessarily in the same boat: Heterogeneous risk assessment among East African pastoralists. Journal of Development Studies, 27(5): $1-30$.

Smith, K., Barrett, C. and Box, P. (2000). Participatory risk mapping for targeting research and assistance: With an example from East African pastoralists. World Development, 28(11): 1945-59.

Tversky, A., and Kahneman, D. (1982). Judgements of and by representativeness, in D. Kahneman, P. Slovic, and A. Tversky ed., Judgment under uncertainty : heuristics and biases, (Cambridge ; New York, Cambridge University Press), pp. 84-98.

World Health Organization. (2002). World Health Report: 2002: Reducing Risks, Promoting Healthy Life. World Health Organization, Geneva, Switzerland. 
Table 1. Descriptive information on study sites

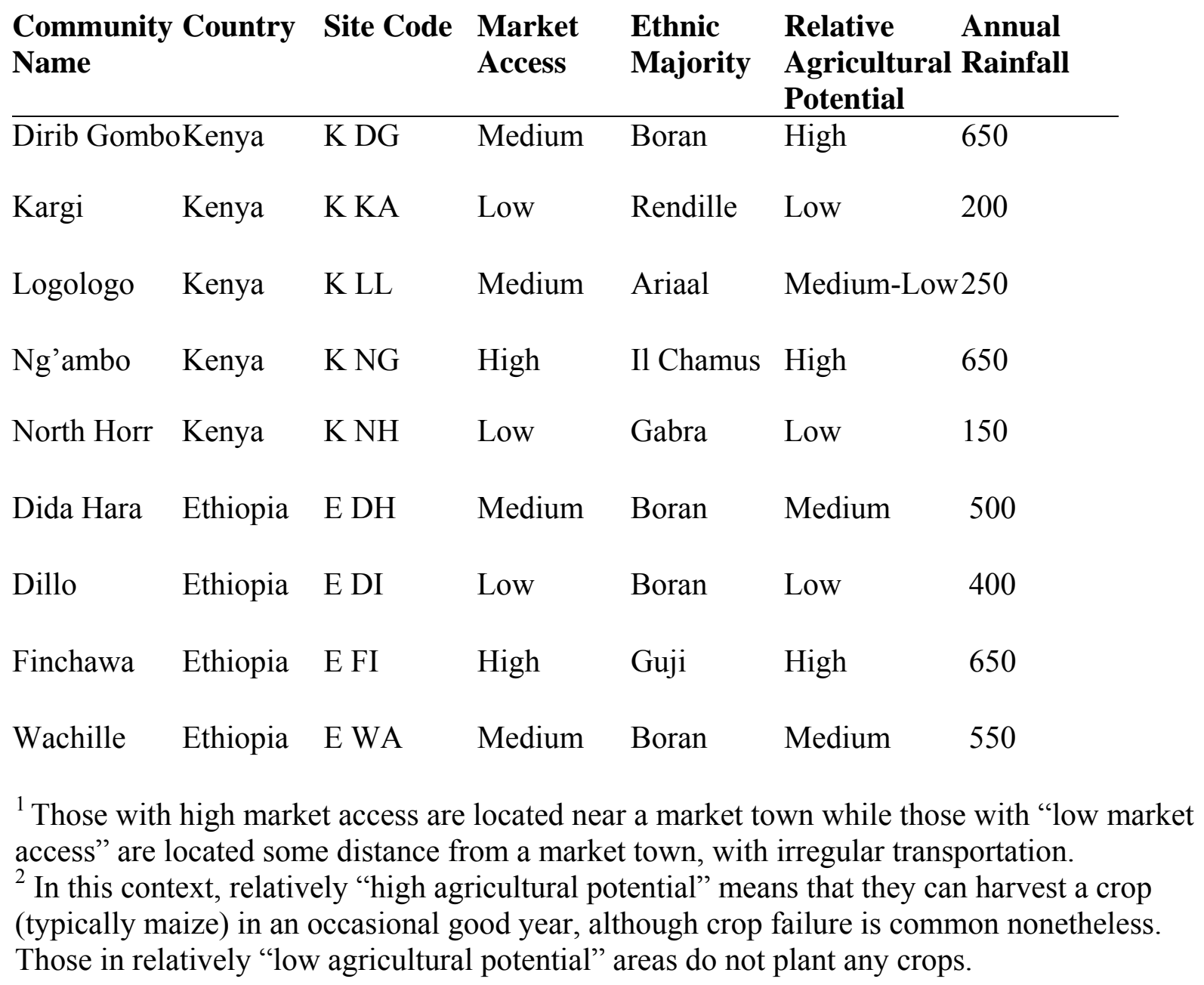


Table 2. Descriptive statistics of variables used in the analysis.

Std.

Mean Dev. Min. Max.

Household Characteristics

TLU

Asset Value (KSh)

$14.62 \quad 25.32$

$6515 \quad 32766$

236

Income over past 3 months* (KSh)

$5778 \quad 11718$

$0.68 \quad 0.43$

Share of income from livestock

0.09

0.26

Share of income from salary

$8.3 \quad 3.6$

$\begin{array}{lr}0 & 236 \\ 0 & 374050 \\ 0 & 121140 \\ 0 & 1 \\ 0 & 1 \\ 1 & 19\end{array}$

Individual Characteristics

Age (years)

Male (1=yes)

45.5

16.5

0.50

16

98

0.47

2.1

0.68

0.29

0.45

0.49

0.50

0.16

0.36

Female head $(1=$ yes $)$

$0.16-0.36$

\section{Community Characteristics}

Average herd size (TLU)

$14.5 \quad 9.1$

2.1

43.2

1 TLU $($ Tropical Livestock Unit $)=0.7$ camel $=1 \mathrm{cow}=10$ sheep $=11$ goats

* Income includes both cash income and the value of goods produced and consumed by the household and remittances. Data from Ethiopia was converted from Ethiopian birr to Kenyan shillings.

Table 3: Overall risk rankings, mean and standard deviation

\begin{tabular}{lll}
\hline Concern & Mean & Std. Dev. \\
Food shortages & 0.58 & 0.36 \\
Human sickness & 0.42 & 0.36 \\
Lack of pasture & 0.39 & 0.40 \\
High consumer prices & 0.35 & 0.29 \\
Animal sickness & 0.35 & 0.34 \\
Insecurity/violence & 0.30 & 0.36 \\
No livestock buyers & 0.29 & 0.28 \\
No water & 0.28 & 0.35 \\
Crop loss & 0.27 & 0.38 \\
Low livestock sales prices & 0.22 & 0.26 \\
Animal loss/theft & 0.16 & 0.25 \\
\hline
\end{tabular}

Scale is $0-1$, with 1 being the highest concern, 0 the lowest. 
Table 4: Means of shock variables

Community Level Shocks

Std.

Mean Dev. Minimum Maximum

Change in community mean household

herd size (TLU)

$\begin{array}{llll}-0.6 & 4.2 & -20.7 & 10.4\end{array}$

Price Deviation

Raid*

$-0.004 \quad 0.12$

$0.14 \quad 0.34$

Quarantine*

Outbreak of Animal Disease*

Outbreak of Human Disease*

Ease of selling

Number of Traders

$0.21 \quad 0.41$

$0.31 \quad 0.46$

$0.44 \quad 0.50$

$\begin{array}{ll}-0.25 & 0.51\end{array}$

$-0.3$

0.4

Rainfall -- past 3 months (mm)

$23 \quad 35$

$92 \quad 91$

Rainfall -- past 6 months (mm)

$175 \quad 123$

$\begin{array}{ll}-0.6 & 10.3\end{array}$

$-124.2$

108.6

$0.27 \quad 0.44$

$0.02 \quad 0.14$

0

0

1

* Dummy variable $=1$ if occurred in preceding 3 months in community, $=0$ otherwise. 
Table 5: Estimation of risk ranking, top five risks overall

\begin{tabular}{|c|c|c|c|c|c|}
\hline Variable Name & $\begin{array}{l}\text { Food } \\
\text { Shortage }\end{array}$ & $\begin{array}{l}\text { Human } \\
\text { Health }\end{array}$ & $\begin{array}{l}\text { Lack of } \\
\text { Pasture }\end{array}$ & $\begin{array}{l}\text { High Consumer } \\
\text { Prices }\end{array}$ & $\begin{array}{l}\text { Animal } \\
\text { Health }\end{array}$ \\
\hline \multicolumn{6}{|l|}{ Community Level } \\
\hline $\begin{array}{l}6 \text { month rainfall } \\
\times 10^{-2}\end{array}$ & $\begin{array}{l}0.3431 * * * \\
(0.0377)\end{array}$ & $\begin{array}{c}0.0450 \\
(0.0348)\end{array}$ & $\begin{array}{l}-0.3440 * * * \\
(0.0446)\end{array}$ & $\begin{array}{c}0.0369 \\
(0.0244)\end{array}$ & $\begin{array}{l}-0.1133 * * * \\
(0.0352)\end{array}$ \\
\hline 6 month rainfall ${ }^{2}$ & $-0.6606 * * *$ & 0.0164 & $0.6029 * * *$ & -0.0060 & 0.1287 \\
\hline $\mathrm{x} 10^{-5}$ & $(0.0903)$ & $(0.0842)$ & $(0.1074)$ & $(0.0580)$ & $(0.0854)$ \\
\hline $\begin{array}{l}3 \text { month/ } 6 \text { month } \\
\text { rainfall }\end{array}$ & $\begin{array}{l}-0.0979 * * * \\
(0.0356)\end{array}$ & $\begin{array}{l}-0.0098 \\
(0.0325)\end{array}$ & $\begin{array}{l}-0.3951 * * * \\
(0.0464)\end{array}$ & $\begin{array}{l}-0.1070 * * * \\
(0.0248)\end{array}$ & $\begin{array}{l}-0.0667 * * \\
(0.0327)\end{array}$ \\
\hline Raid & $\begin{array}{l}0.1779 * * * \\
(0.0304)\end{array}$ & $\begin{array}{l}-0.1450 * * * \\
(0.0291)\end{array}$ & $\begin{array}{l}-0.1747 * * * \\
(0.0363)\end{array}$ & $\begin{array}{l}-0.0046 \\
(0.0204)\end{array}$ & $\begin{array}{l}-0.2471 * * * \\
(0.0291)\end{array}$ \\
\hline Quarantine & $\begin{array}{c}0.0354 \\
(0.0383)\end{array}$ & $\begin{array}{l}-0.0150 \\
(0.0352)\end{array}$ & $\begin{array}{l}-0.1046 * * \\
(0.0432)\end{array}$ & $\begin{array}{l}-0.0115 \\
(0.0252)\end{array}$ & $\begin{array}{l}-0.1034 * * * \\
(0.0349)\end{array}$ \\
\hline Ease sell & $\begin{array}{l}-0.0150 \\
(0.0258)\end{array}$ & $\begin{array}{l}-0.0400 * \\
(0.0241)\end{array}$ & $\begin{array}{l}0.2539 * * * \\
(0.0301)\end{array}$ & $\begin{array}{l}-0.0877 * * * \\
(0.0176)\end{array}$ & $\begin{array}{l}-0.0130 \\
(0.0237)\end{array}$ \\
\hline \# Traders & $\begin{array}{l}-0.0012 \\
(0.0014)\end{array}$ & $\begin{array}{l}0.0075 * * * \\
(0.0013)\end{array}$ & $\begin{array}{l}0.0068 * * * \\
(0.0017)\end{array}$ & $\begin{array}{c}0.0001 \\
(0.0009)\end{array}$ & $\begin{array}{l}0.0052 * * * \\
(0.0014)\end{array}$ \\
\hline Animal disease & $\begin{array}{l}-0.0565 * \\
(0.0311)\end{array}$ & $\begin{array}{l}0.0331 \\
(0.0295)\end{array}$ & $\begin{array}{l}-0.0638 * \\
(0.0372)\end{array}$ & $\begin{array}{l}0.0071 \\
(0.0210)\end{array}$ & $\begin{array}{l}-0.0111 \\
(0.0289)\end{array}$ \\
\hline Human disease & $\begin{array}{l}-0.1187 * * * \\
(0.0199)\end{array}$ & $\begin{array}{c}0.0075 \\
(0.0189)\end{array}$ & $\begin{array}{c}0.0086 \\
(0.0239)\end{array}$ & $\begin{array}{l}-0.0092 \\
(0.0133)\end{array}$ & $\begin{array}{l}-0.0223 \\
(0.0187)\end{array}$ \\
\hline Price deviation & $\begin{array}{l}-0.2531 * * \\
(0.1052)\end{array}$ & $\begin{array}{l}0.4681 * * * \\
(0.1000)\end{array}$ & $\begin{array}{l}0.1020 \\
(0.1322)\end{array}$ & $\begin{array}{l}0.1782 * * \\
(0.0694)\end{array}$ & $\begin{array}{l}0.2544 * * \\
(0.1004)\end{array}$ \\
\hline Community average & $-0.0201 * * *$ & $-0.0163 * * *$ & $0.0512 * * *$ & $-0.0117 * * *$ & -0.0001 \\
\hline TLU & $(0.0038)$ & $(0.0036)$ & $(0.0045)$ & $(0.0025)$ & $(0.0035)$ \\
\hline $\begin{array}{l}\text { Community average } \\
\triangle T L U\end{array}$ & $\begin{array}{l}0.0139 * * * \\
(0.0026)\end{array}$ & $\begin{array}{l}-0.0018 \\
(0.0023)\end{array}$ & $\begin{array}{l}-0.0221 * * * \\
(0.0029)\end{array}$ & $\begin{array}{l}0.0039 * * \\
(0.0016)\end{array}$ & $\begin{array}{l}-0.0098 * * * \\
(0.0023)\end{array}$ \\
\hline \multicolumn{6}{|l|}{ Household Level } \\
\hline $\begin{array}{l}\text { TLU } \\
\times 10^{-1}\end{array}$ & $\begin{array}{l}-0.0023 \\
(0.0038)\end{array}$ & $\begin{array}{c}0.0019 \\
(0.0035)\end{array}$ & $\begin{array}{c}0.0038 \\
(0.0043)\end{array}$ & $\begin{array}{l}-0.0069 * * * \\
(0.0025)\end{array}$ & $\begin{array}{c}0.0004 \\
(0.0035)\end{array}$ \\
\hline$\Delta \mathrm{TLU}$ & $\begin{array}{l}-0.0015 * \\
(0.0009)\end{array}$ & $\begin{array}{l}0.0002 \\
(0.0008)\end{array}$ & $\begin{array}{l}0.0006 \\
(0.0010)\end{array}$ & $\begin{array}{l}-0.0003 \\
(0.0005)\end{array}$ & $\begin{array}{l}0.0006 \\
(0.0007)\end{array}$ \\
\hline $\begin{array}{l}\text { Household } \\
\text { Size }\end{array}$ & $\begin{array}{l}-0.0085 * * * \\
(0.0029)\end{array}$ & $\begin{array}{l}-0.0016 \\
(0.0027)\end{array}$ & $\begin{array}{l}0.0020 \\
(0.0034)\end{array}$ & $\begin{array}{l}-0.0014 \\
(0.0019)\end{array}$ & $\begin{array}{l}0.0015 \\
(0.0027)\end{array}$ \\
\hline $\begin{array}{l}\text { Asset value } \\
\times 10^{-3}\end{array}$ & $\begin{array}{l}-0.0009 * * * \\
(0.0003)\end{array}$ & $\begin{array}{l}-0.0007 * * \\
(0.0003)\end{array}$ & $\begin{array}{l}-0.0005 \\
(0.0003)\end{array}$ & $\begin{array}{l}0.0003 \\
(0.0002)\end{array}$ & $\begin{array}{l}-0.0008 * * * \\
(0.0003)\end{array}$ \\
\hline $\begin{array}{l}\text { Income } \\
\times 10^{-4}\end{array}$ & $\begin{array}{l}-0.0050 \\
(0.0090)\end{array}$ & $\begin{array}{l}0.0242 * * * \\
(0.0081)\end{array}$ & $\begin{array}{l}0.0397 * * * \\
(0.0106)\end{array}$ & $\begin{array}{l}0.0050 \\
(0.0061)\end{array}$ & $\begin{array}{l}0.0485 * * * \\
(0.0080)\end{array}$ \\
\hline $\begin{array}{l}\text { Livestock share of } \\
\text { income }\end{array}$ & $\begin{array}{l}-0.0049 \\
(0.0230)\end{array}$ & $\begin{array}{l}0.0108 \\
(0.0215)\end{array}$ & $\begin{array}{l}0.0365 \\
(0.0269)\end{array}$ & $\begin{array}{l}-0.0068 \\
(0.0150)\end{array}$ & $\begin{array}{l}0.0402 * \\
(0.0214)\end{array}$ \\
\hline $\begin{array}{l}\text { Salary share of } \\
\text { income }\end{array}$ & $\begin{array}{l}0.0130 \\
(0.0389)\end{array}$ & $\begin{array}{l}-0.0286 \\
(0.0368)\end{array}$ & $\begin{array}{l}-0.0699 \\
(0.0495)\end{array}$ & $\begin{array}{l}-0.0508 * \\
(0.0265)\end{array}$ & $\begin{array}{l}-0.0571 \\
(0.0365)\end{array}$ \\
\hline Illness & $\begin{array}{l}0.0349 * \\
(0.0209)\end{array}$ & $\begin{array}{c}0.0101 \\
(0.0193)\end{array}$ & $\begin{array}{l}0.0079 \\
(0.0243)\end{array}$ & $\begin{array}{l}0.0291 * * \\
(0.0137)\end{array}$ & $\begin{array}{l}-0.0308 \\
(0.0193)\end{array}$ \\
\hline Death & $\begin{array}{c}0.0841 \\
(0.0624)\end{array}$ & $\begin{array}{l}-0.0577 \\
(0.0561)\end{array}$ & $\begin{array}{c}0.0591 \\
(0.0683)\end{array}$ & $\begin{array}{l}0.0583 \\
(0.0384)\end{array}$ & $\begin{array}{l}-0.0124 \\
(0.0558)\end{array}$ \\
\hline
\end{tabular}




\section{Table 5 (continued)}

\begin{tabular}{|c|c|c|c|c|c|}
\hline Variable Name & $\begin{array}{l}\text { Food } \\
\text { Shortage }\end{array}$ & $\begin{array}{l}\text { Human } \\
\text { Health }\end{array}$ & $\begin{array}{l}\text { Lack of } \\
\text { Pasture }\end{array}$ & $\begin{array}{l}\text { High Consumer } \\
\text { Prices }\end{array}$ & $\begin{array}{l}\text { Animal } \\
\text { Health }\end{array}$ \\
\hline \multicolumn{6}{|l|}{ Individual Level } \\
\hline Age & $\begin{array}{l}-0.0002 \\
(0.0005)\end{array}$ & $\begin{array}{c}0.0005 \\
(0.0005)\end{array}$ & $\begin{array}{l}-0.0007 \\
(0.0006)\end{array}$ & $\begin{array}{l}-0.0002 \\
(0.0003)\end{array}$ & $\begin{array}{l}-0.0006 \\
(0.0005)\end{array}$ \\
\hline Male & $\begin{array}{l}-0.0158 \\
(0.0357)\end{array}$ & $\begin{array}{l}-0.0040 \\
(0.0335)\end{array}$ & $\begin{array}{l}0.1053 * * \\
(0.0418)\end{array}$ & $\begin{array}{c}0.0208 \\
(0.0233)\end{array}$ & $\begin{array}{c}0.0375 \\
(0.0336)\end{array}$ \\
\hline Highest Education & 0.0007 & 0.0057 & -0.0050 & 0.0007 & -0.0039 \\
\hline Level & $(0.0044)$ & $(0.0041)$ & $(0.0055)$ & $(0.0030)$ & $(0.0040)$ \\
\hline Wife & $\begin{array}{l}-0.0091 \\
(0.0325)\end{array}$ & $\begin{array}{c}0.0212 \\
(0.0205)\end{array}$ & $\begin{array}{c}0.0605 \\
(0.0384)\end{array}$ & $\begin{array}{c}0.0293 \\
(0.0212)\end{array}$ & $\begin{array}{c}0.0366 \\
(0.0307)\end{array}$ \\
\hline Head & $\begin{array}{c}0.0126 \\
(0.0267)\end{array}$ & $\begin{array}{c}0.0181 \\
(0.0248)\end{array}$ & $\begin{array}{l}0.0641 * * \\
(0.0306)\end{array}$ & $\begin{array}{c}0.0011 \\
(0.0174)\end{array}$ & $\begin{array}{l}0.0686 * * * \\
(0.0248)\end{array}$ \\
\hline Female & 0.0193 & -0.0190 & 0.0105 & $0.0513 *$ & -0.0296 \\
\hline Head & $(0.0438)$ & $(0.0408)$ & $(0.0512)$ & $(0.0287)$ & $(0.0408)$ \\
\hline \multicolumn{6}{|l|}{ Regression Details } \\
\hline Sigma & $\begin{array}{l}0.4840 * * * \\
(0.0078)\end{array}$ & $\begin{array}{l}0.4456 * * * \\
(0.0070)\end{array}$ & $\begin{array}{l}0.5291 * * * \\
(0.0096)\end{array}$ & $\begin{array}{l}0.3260 * * * \\
(0.0045)\end{array}$ & $\begin{array}{l}0.4379 * * * \\
(0.0071)\end{array}$ \\
\hline Pseudo $\mathrm{R}^{2}$ (Decomp) & 0.48 & 0.24 & 0.26 & 0.32 & 0.18 \\
\hline Number of obs. & 4104 & 4104 & 4104 & 4104 & 4104 \\
\hline
\end{tabular}

Time period and site specific dummies are not reported

Table 6: Simulated risk rankings for Finchawa, with individual specific variables changing.

\begin{tabular}{|c|c|c|c|c|c|}
\hline & $\begin{array}{l}\text { Food } \\
\text { Shortages }\end{array}$ & $\begin{array}{l}\text { Human } \\
\text { Health }\end{array}$ & $\begin{array}{l}\text { High consumer } \\
\text { prices }\end{array}$ & $\begin{array}{l}\text { Lack of } \\
\text { pasture }\end{array}$ & $\begin{array}{l}\text { Animal } \\
\text { health }\end{array}$ \\
\hline Male & 0.741 & 0.206 & 0.121 & 0.109 & 0.092 \\
\hline Female & 0.750 & 0.204 & 0.132 & 0.107 & 0.098 \\
\hline
\end{tabular}


Figure 1: Risk ranking by gender for all risks.

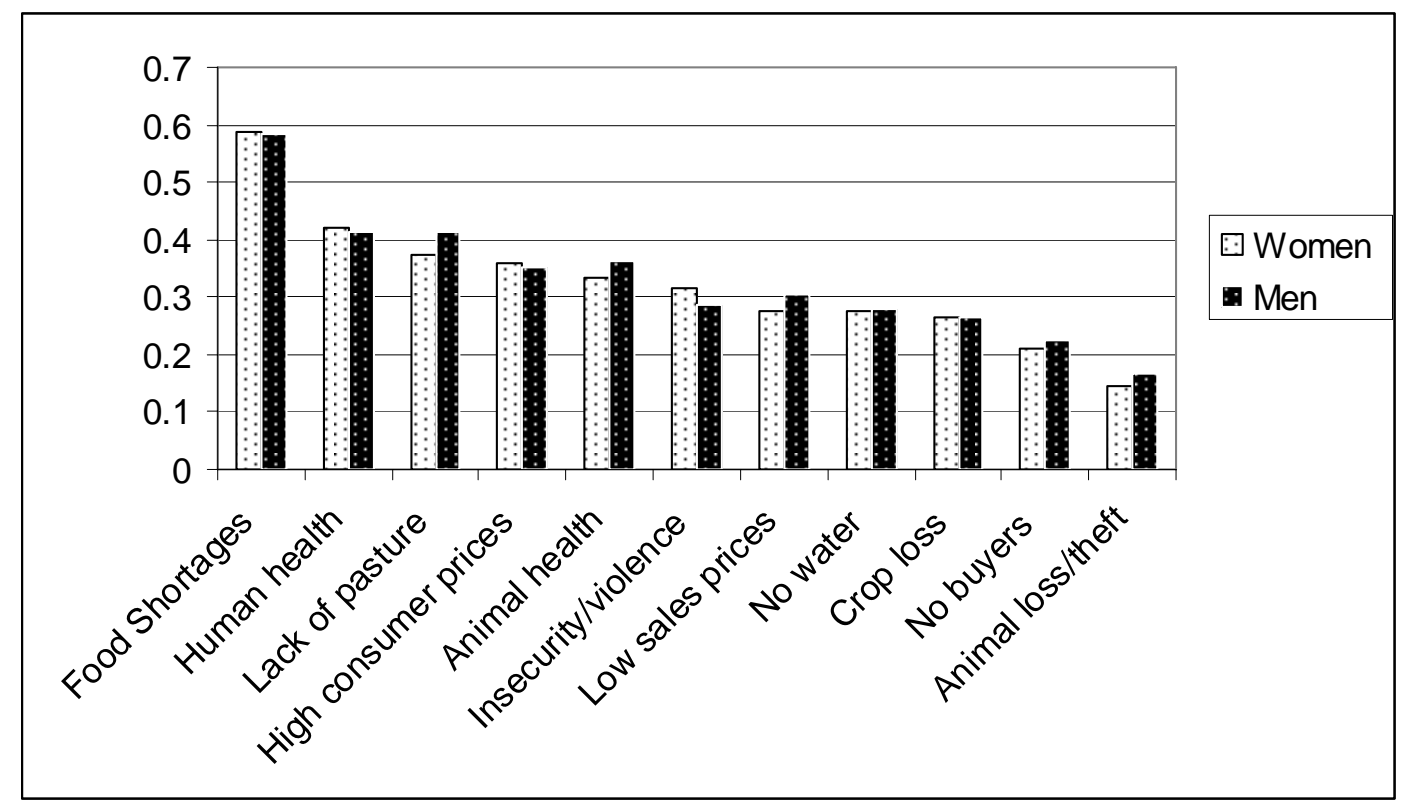

Figure 2: Risk ranking by site, top five concerns.

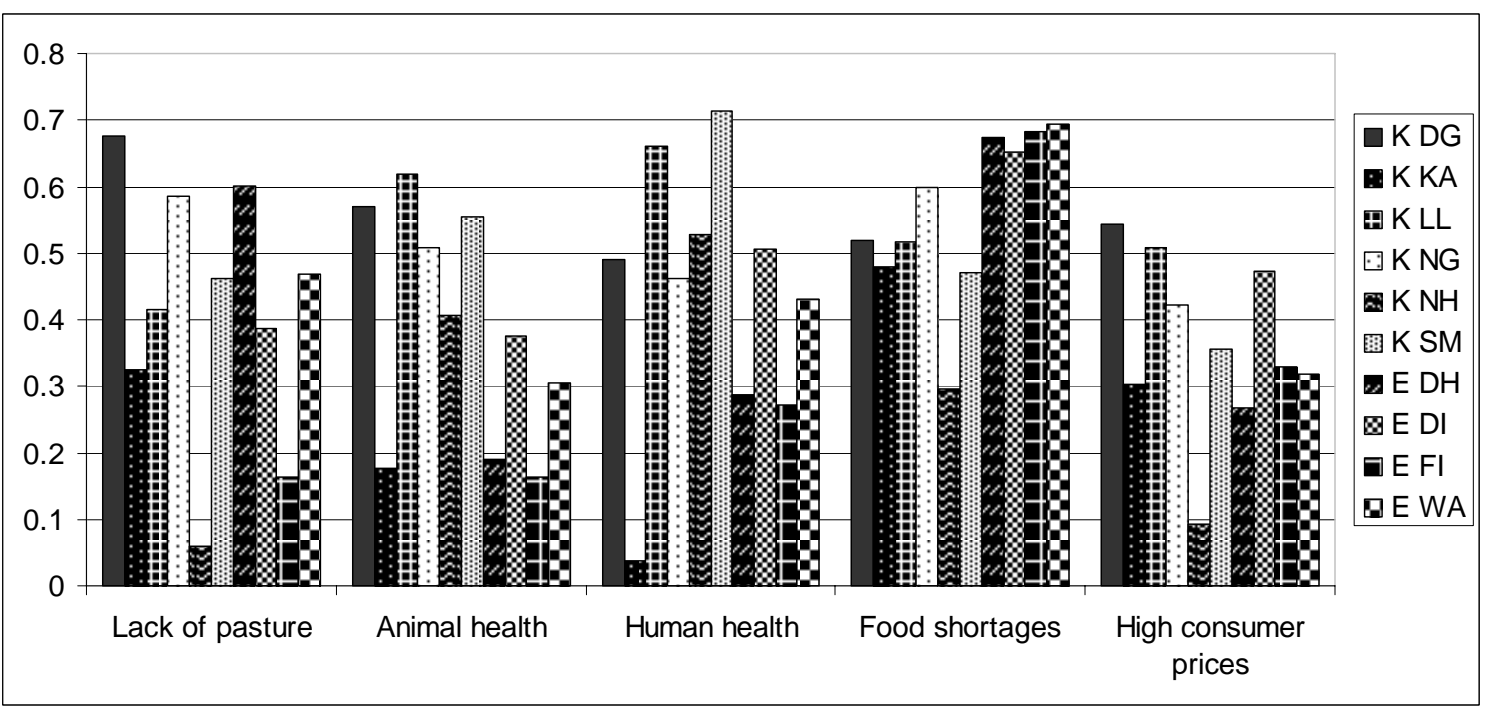


Figure 3: Risk ranking over time for top five concerns.

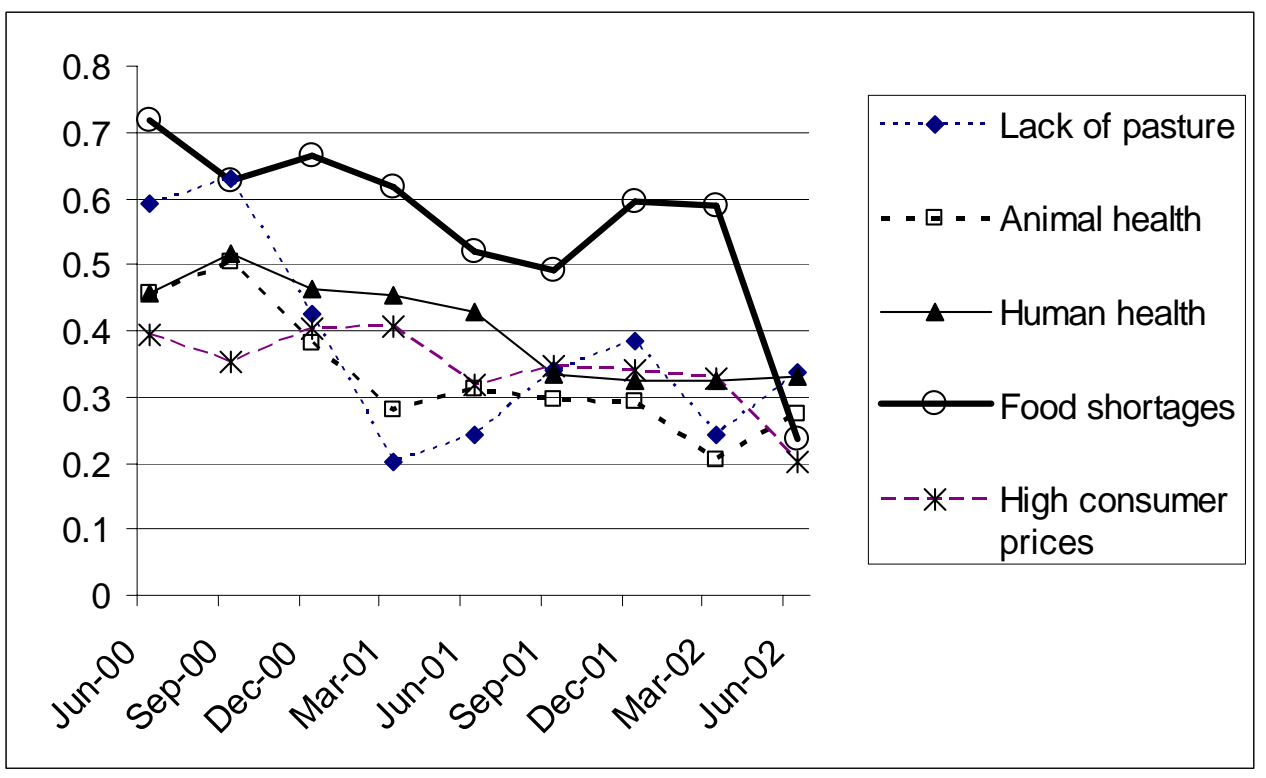

Figure 4: Simulated risk rankings for top five concerns in North Horr over time.

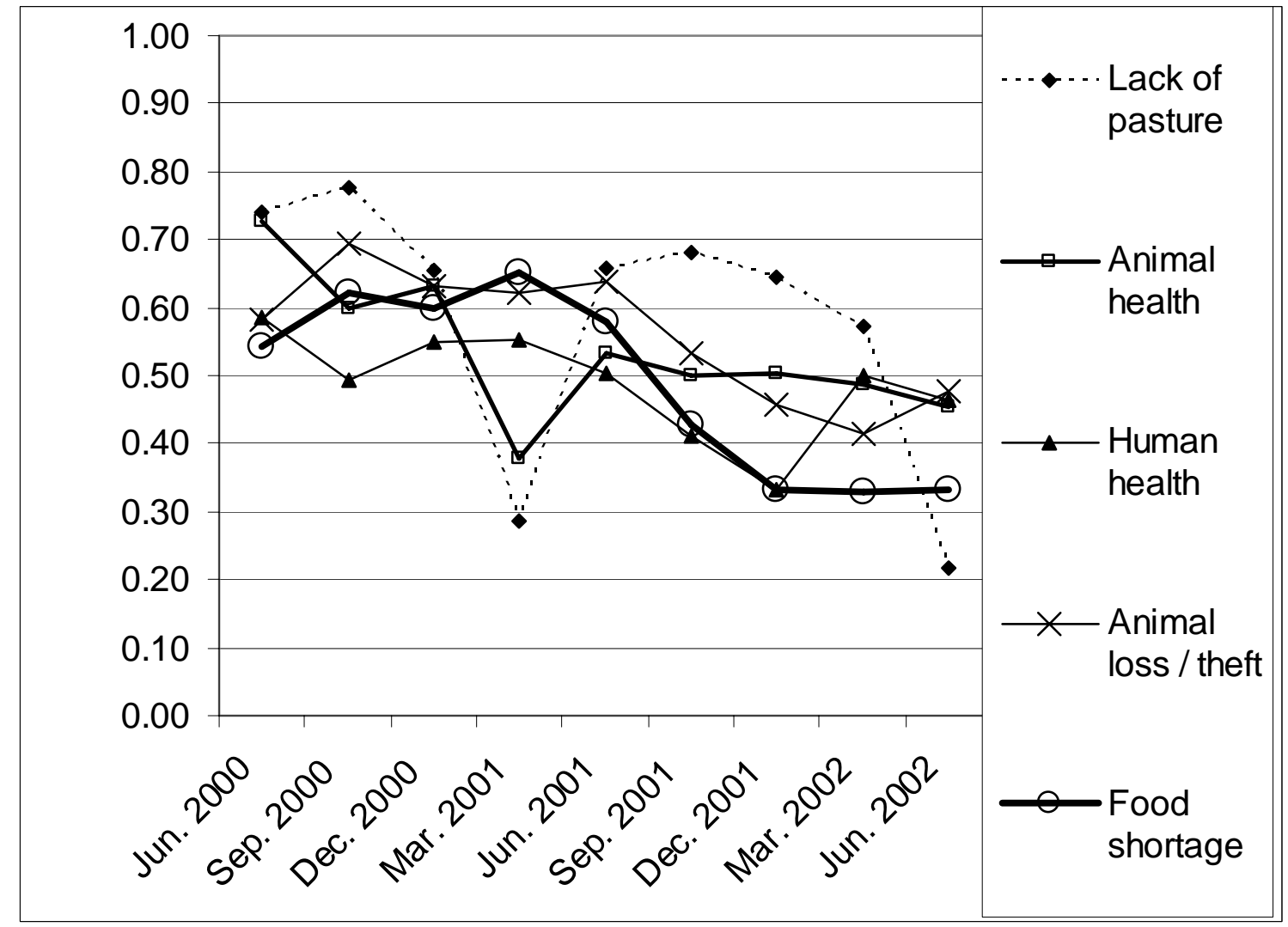


Figure 5: Simulated risk ranking for food shortages, North Horr and Finchawa.

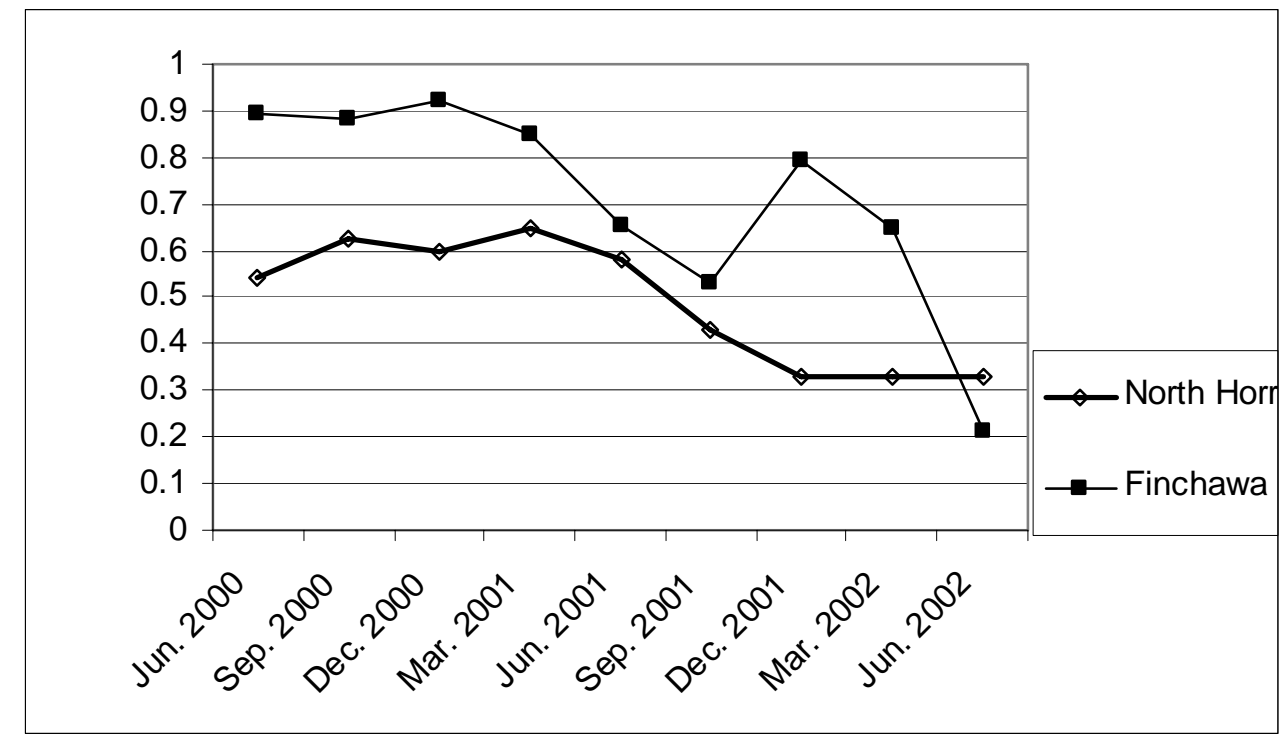

Figure 6: Simulated risk rankings for food shortages by highest and lowest herd size quartiles in North Horr and Finchawa.

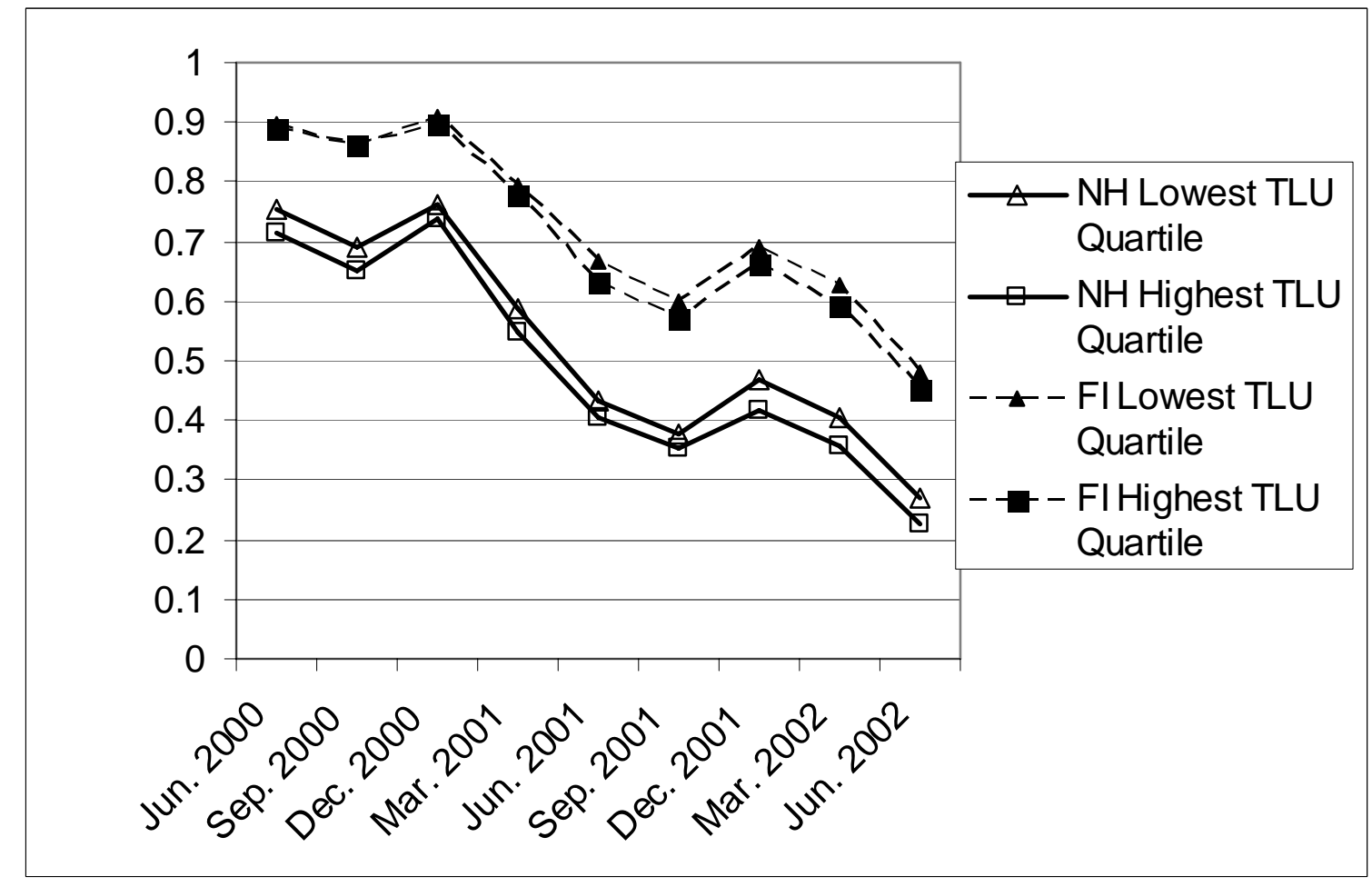

